\title{
Research on the Multi-Energy Management Strategy of the Electric Drive System of a Tracked Bulldozer
}

\author{
Ming Pan, Jun Yan, Qunzhang Tu, and Chengming Jiang \\ College of Field Engineering, PLA University of Science and Technology, Nanjing 210007, China \\ Correspondence should be addressed to Qunzhang Tu; tqzlhnj@126.com
}

Received 10 October 2015; Accepted 14 February 2016

Academic Editor: Ivano Benedetti

Copyright ( 2016 Ming Pan et al. This is an open access article distributed under the Creative Commons Attribution License, which permits unrestricted use, distribution, and reproduction in any medium, provided the original work is properly cited.

\begin{abstract}
The multi-energy management strategy of electric drive system of tracked bulldozer was researched. Firstly, based on power requirement of typical working condition of a tracked bulldozer, the power distribution strategy for three energy sources in the front power chain was proposed by using wavelet theory and fuzzy control theory. Secondly, the electric drive system simulation platform was built in MATLAB/Simulink. At last, a driver-controller based HILS (hardware-in-the-loop simulation) platform was built and the multi-energy management strategy was verified. The HILS result shows that front power chain's power output can meet the back power chain's requirement, the engine-generator set works near the best fuel consumption curve, and the battery pack's charge-discharge frequency and current are low. Thus the designed multi-energy management strategy can be used in real-time control of electric drive bulldozer.
\end{abstract}

\section{Introduction}

Nowadays, energy saving and environmental protection have become more and more important [1]. In order to mitigate environmental issues caused by petroleum combustion [2], the electric drive technique has been widely used in areas such as automobile, engineering machinery, ship, and harbor hoisting machinery. As a key technology of electric drive system, the energy management strategy (EMS) has been studied extensively and deeply in order to improve the electric drive system's performance. EMS used in electric system can be mainly divided into four kinds.

(1) Rule-Based Logic Threshold Control Strategy. In [3], a rule-based strategy (RBS) for plug in hybrid electric vehicle (PHEV) was proposed. The PHEV operated in different modes which were determined by control rules designed based on state of charge (SOC) of the battery, power requirement, vehicle speed, and engine coolant temperature. Simulation results show that, with the proposed RBS energy management strategy, the gas mileage of the PHEV increased by $16 \%$ over the Prius control strategy.
In [4], the regenerative braking strategy, used to distribute braking torque between electric braking system and mechanical braking system, was designed by setting switch thresholds of brake pedal travel and battery SOC.

Although rule-based logic threshold control strategy is simple and practical, the setting of threshold relies too much on experience and experimental data, while the actual control effect is not good.

(2) Fuzzy Logic Control Strategy. The basic idea of such strategy is to formulate a collection of fuzzy IF-THEN rules from human knowledge and reasoning, which offers a qualitative description of controlled system $[2,5]$.

Baumann et al. [6] and Lee and Sul [7] propose a fuzzy logic based torque control strategy for parallel HEVs in 1998. After that, the fuzzy control method was also used in series HEVs [8] and series-parallel HEVs [9].

In order to improve the performance of fuzzy controller, intelligent optimal algorithms such as GA [10], PSO [11], and BA [12] were adopted to optimize membership function and fuzzy rules. Furthermore, the adaptive neural fuzzy inference system (ANFIS) [13], machine learning algorithm [14], and 


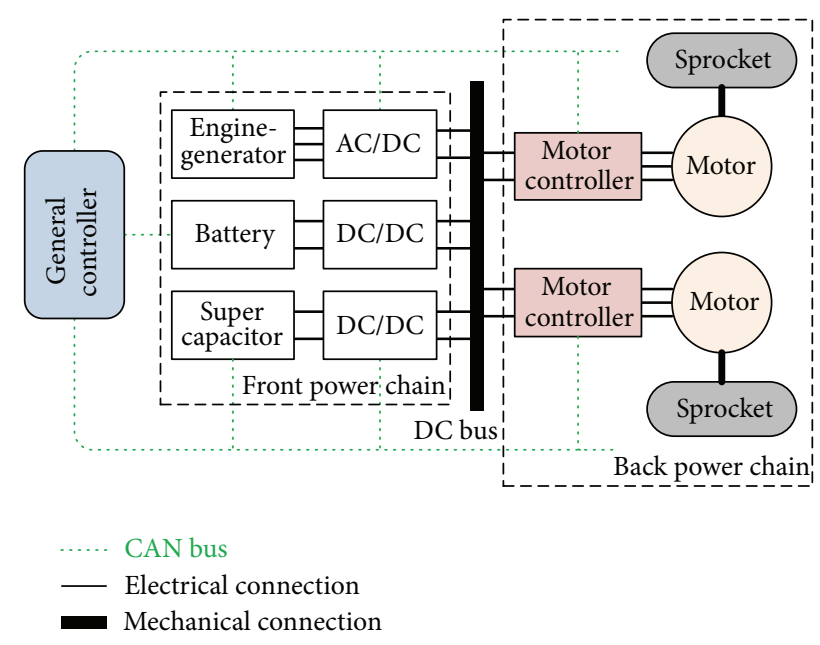

FIGURE 1: Structure diagram of series electric drive system.

driving cycle recognition $[15,16]$ were introduced to fuzzy control strategy.

(3) Dynamic Program (DP). DP is a kind of mathematical method used to solve optimization problems which has been widely used in engineering fields. The main idea of DP is to divide the target optimization problem into several subproblems; then the global optimization solution of the target problem can be achieved by computing local optimal solution of subproblems.

In [17], Koot combined traditional control method with DP and the fuel economy was improved by $3 \sim 5 \%$. In [18], the stochastic dynamic program method was proposed by Liu and Peng. Dynamic models of the hybrid electric drive system was built and the global optimization control strategy was designed.

(4) Local Instantaneous Optimization Strategy. The output torque of the hybrid system was controlled in order to lower the equivalent fuel consumption. In $[19,20]$, the equivalent fuel consumption per hour was calculated by converting charging energy into fuel combustion of the engine. The simulation results show that the fuel efficiency of local instantaneous optimization strategy is better than the rulebased control strategy and it can be used in unknown driving condition. However, the calculation is very time-consuming and the real-time control of automobiles cannot be achieved by instantaneous optimization strategy.

The application of electric drive technique in bulldozer is still in beginning stages; there is only one kind of electric drive bulldozer which is launched by Caterpillar Inc. at present. The relevant energy management strategy is rarely researched. The control strategy of bulldozer driving condition is similar to armored tracked vehicle which can be taken as a reference, but in bulldozing condition, the power requirement of the back power chain is quite different from automobile and armored vehicle. The control strategies mentioned above are not suitable for bulldozing condition, so that the multi-energy management in bulldozing condition is a difficult issue to resolve for electric drive dozer.
The electric drive bulldozer contains 3 power sources: an engine-generator set, a battery pack, and a supercapacitor. The energy distribution strategy among these power sources determines the dynamic performance, fuel economy, and service life of critical components. Thus the multi-energy management strategy was built based on wavelet theory and fuzzy control theory. The strategy makes output and requirement of power meet when distributing output of the three power sources. Furthermore, the strategy also considers the effects of changing frequency of power requirement on engine-generator set, battery pack, and supercapacitor. The supercapacitor has an advantage of quickly responding to high frequent power requirement, so that the enginegenerator set would work steadily in the best fuel economy interval and the charge-discharge frequency and current are lower which are conductive to improve battery's working life.

\section{Structure of the Electric Drive System}

The series electric drive system was adopted and there is one motor on both sides to drive the sprocket of the bulldozer, as shown in Figure 1.

The system contains a general controller, an enginegenerator set, a rectifier, a battery pack, a supercapacitor, the bidirectional DC/DC converter, two driving motors, and two motors' controllers. The engine-generator set, battery pack, and supercapacitor make up the front power chain which provides energy for the whole system. The driving motors, motors' controllers, and sprockets compose the back power chain. There is not any mechanical joint between the front and the back power chain, so the electric drive structure is simple which can be easily arranged in the limited space of the bulldozer.

\section{Multi-Energy Management Strategy Design}

3.1. Analysis of Energy Requirement of Bulldozing Condition. A typical dozer working condition is shown in Figure 2. In this working condition, shoveling, muck haulage, dumping, 


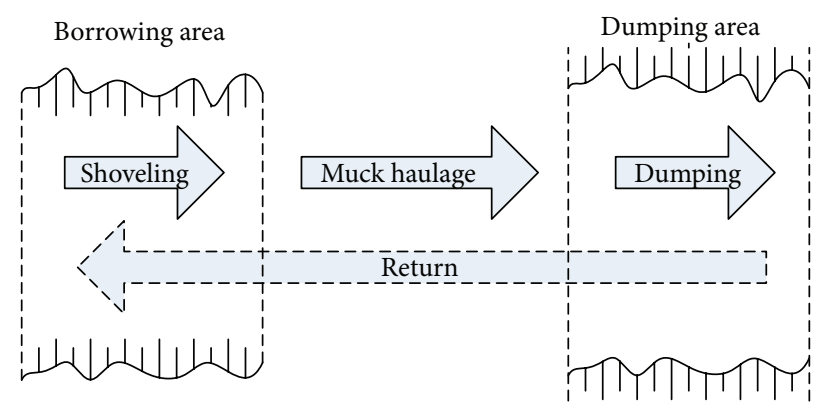

FIGURE 2: Typical bulldozing condition.

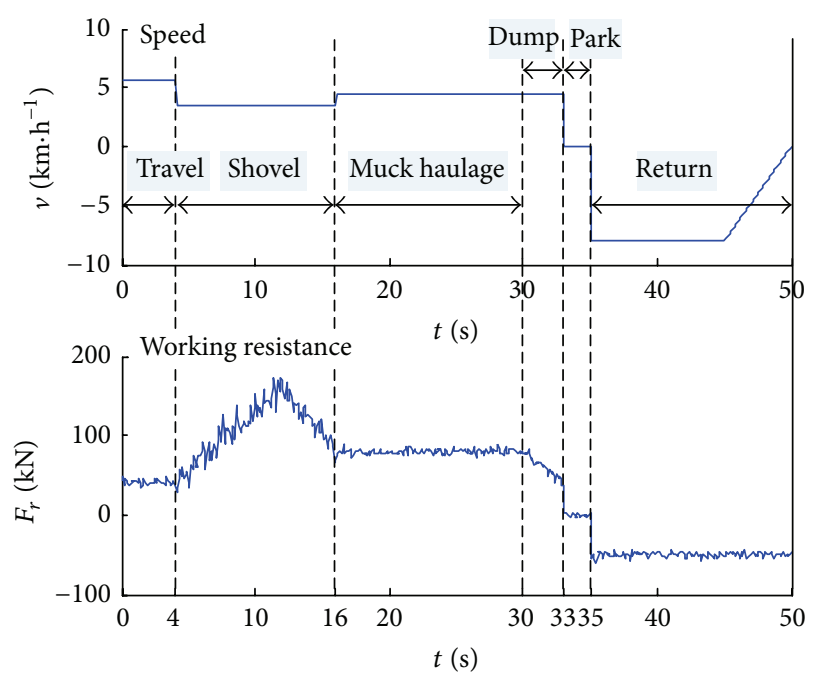

FIGURE 3: Target speed and working resistance.

and returning are basically operated in a line. The driving distance of this bulldozing method is short and the former operation provides favorable conditions for the latter, which is normally used in trenching, soil gathering, and roadbed construction [21].

The bulldozer operates in this mode: $0 \sim 4 \mathrm{~s}$ travelling without load, 4 16 s shoveling, 16 30 s muck haulage, 30 33 s dumping, 33 35 s parking, and 35 50 s reversing. The target speed and working resistance of the bulldozer are shown in Figure 3. It is observed from Figure 3 that bulldozer's working resistance is undulate, especially in shoveling period. The undulation is caused by variation of soil cutting depth and hard barriers which impose impact load on the shovel blade. So there is instantaneous power requirement in high frequency of the back power chain which is shown in Figure 4.

Among the three power sources of the front power chain, the engine-generator set's response is slow and the battery pack is not suitable to charge and discharge in high frequency or with too heavy current [22], so both of them are not convenient to handle this part of power requirement. On the contrary, the power density and charge-discharge cycles of the supercapacitor are much higher than the battery which is good for fast responding to instantaneous energy requirement $[23,24]$.

Based on energy requirement of the back power chain and characteristics of each of power sources, the energy management strategy was designed by combining wavelet theory with fuzzy control theory, as shown in Figure 5.

The power requirement signal was firstly processed by wavelet transform, high frequent part of the power requirement $\left(P_{\text {com_HF }}\right)$ was distributed to the supercapacitor, and the capacitor's operating mode is determined by its state of charge $\left(\mathrm{SOC}_{\mathrm{UC}}\right)$. After wavelet transform, the power requirement signal only contains low frequent part $\left(P_{\text {com_LF }}\right)$.

(1) If $P_{\text {com_LF }}>0$, the bulldozer was in drive mode, and the outputs of the engine-generator set and the battery are determined by the distribution coefficient $x_{\mathrm{fA}}$, which is calculated by fuzzy controller A:

$$
\begin{aligned}
& P_{\text {gen }}=x_{\mathrm{fA}} \cdot P_{\text {com } \_ \text {LF }} \\
& P_{\text {bat }}=\left(1-x_{\mathrm{fA}}\right) \cdot P_{\text {com } \_\mathrm{LF}} .
\end{aligned}
$$




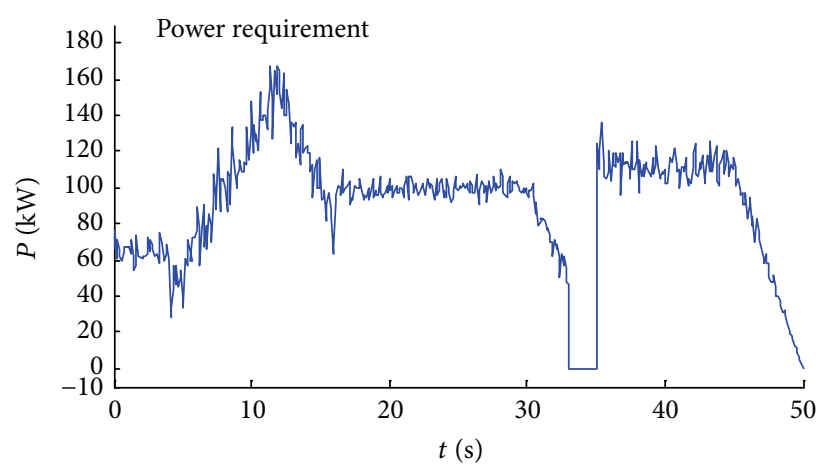

FIgURE 4: Power requirement of the back power chain.

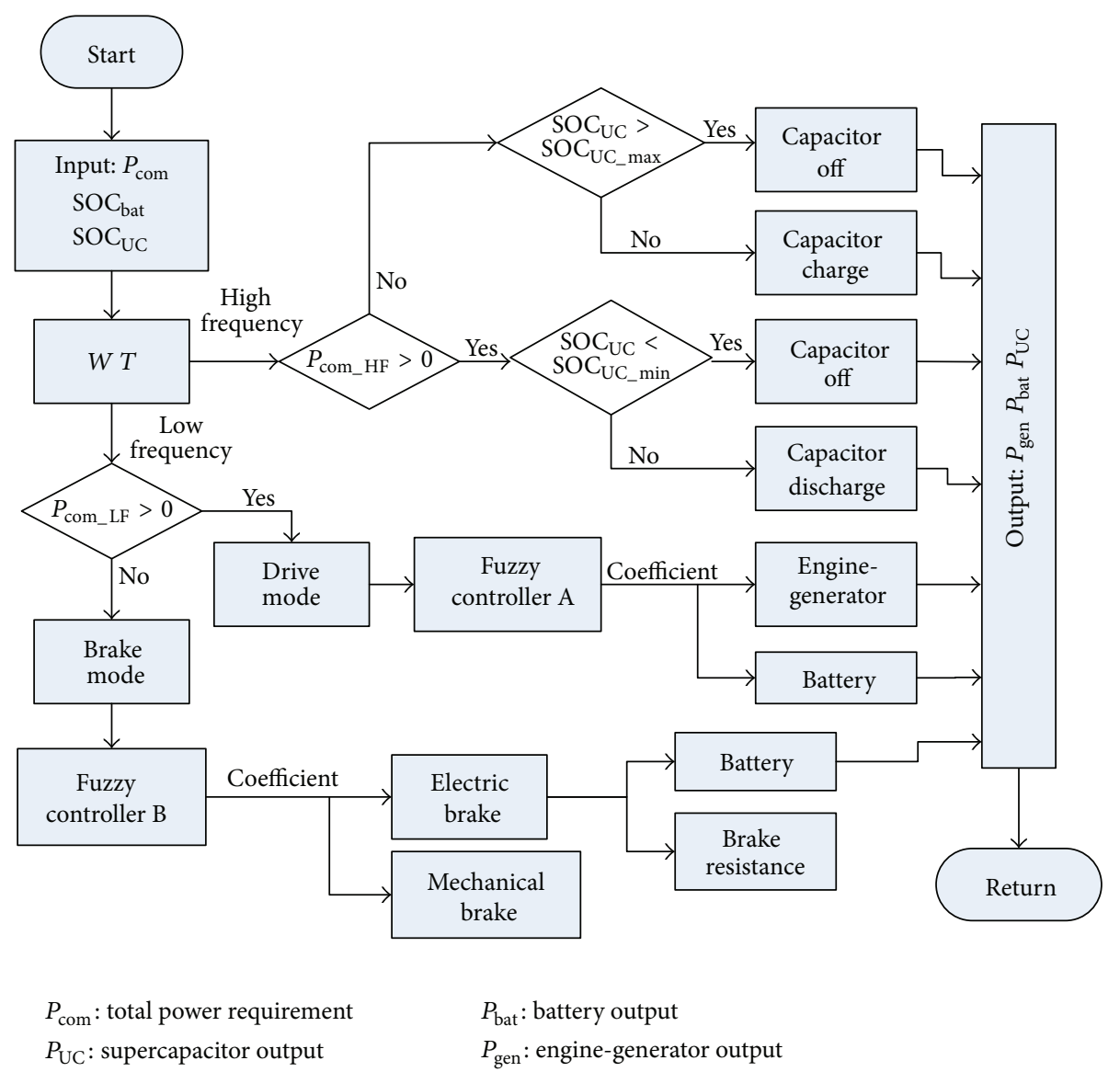

FIGURE 5: Multi-energy management strategy of the electric drive system.

(2) If $P_{\text {com_LF }}<0$, the bulldozer is in brake mode, and the brake torque of the electric brake and the mechanical brake is calculated as follow:

$$
\begin{aligned}
T_{\mathrm{b} \_\mathrm{E}} & =x_{\mathrm{fB}} \frac{P_{\text {com_LF }}}{\omega} . \\
T_{\mathrm{b} \_\mathrm{M}} & =\left(1-x_{\mathrm{fB}}\right) \frac{P_{\text {com_LF }}}{\omega},
\end{aligned}
$$

where $T_{\mathrm{b} \_\mathrm{E}}$ is Electric brake torque, $T_{\mathrm{b} \_\mathrm{M}}$ is Mechanical brake torque, $\omega$ is angular speed of the motor, and $x_{\mathrm{fB}}$ is the distribution ratio calculated by fuzzy controller B.

3.2. Wavelet Transform (WT). WT can extract signal information in both time and frequency domain, and it can decompose signal in different phase and scale. Wavelets with local characteristic are especially suitable for instantaneous signal extraction [25]. As the signal of power requirement is discrete in one dimension, the discrete wavelet transform (DWT) is used to decompose it in different levels. 


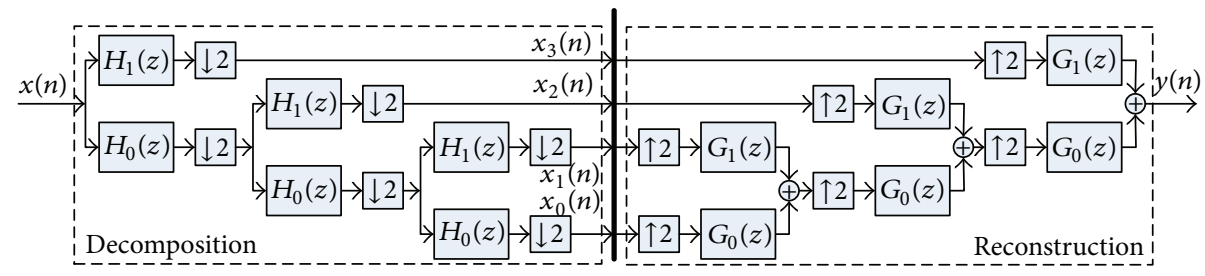

FIgURE 6: Decomposition and reconstruction process of 3-order Haar DWT.

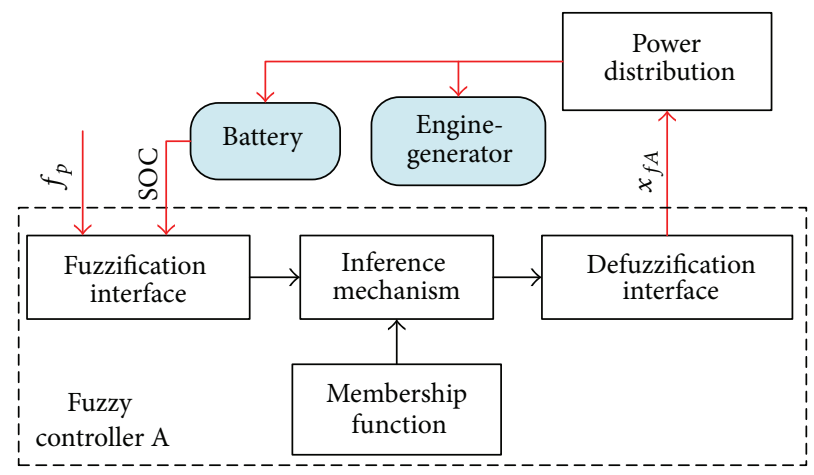

FIGURE 7: Block diagram of fuzzy controller A.

The DWT and IDWT (inverse discrete wavelet transform) are

$$
\begin{aligned}
W(\lambda, \mu) & ={ }_{R} \int x(t) \frac{1}{\sqrt{\lambda}} \Phi\left(\frac{t-\mu}{\lambda}\right) d t \\
x(t) & =\sum_{j \in Z} \sum_{k \in Z} W(j, k) \Phi_{j, k}(t),
\end{aligned}
$$

where $x(t)$ is original signal; $\lambda$ is scale factor, $\lambda=2^{j}, j \in Z$; $\Phi$ is mother wavelet; $\mu$ is shift factor, $\mu=k 2^{j}$ and $j, k \in Z$; W is wavelet coefficient.

Comparing with other common wavelets, the generating function of Haar wavelet has the shortest filter length in time domain and the transformation and inverse transformation are the same. So the decomposition process of Haar wavelet is much simpler than other wavelets, which makes it feasible to extract transient signal in real-time control of electric drive bulldozer. The expression of Haar wavelet is

$$
\Phi(t)= \begin{cases}1 & t \in(0,0.5) \\ -1 & t \in(0.5,1) \\ 0 & \text { others. }\end{cases}
$$

A two-channel filter bank based on Haar wavelet was adopted. The original signal $x(t)$ was decomposed into reference signal and detail signal by a low-pass filter $H_{0}(z)$ and a high-pass filter $H_{1}(z)$, and the signal was rebuilt by reconstruction filter bank $\left[G_{1}(z), G_{0}(z)\right]^{T}[26]$. The decomposition and reconstruction processes of 3-order DWT based on Haar wavelet are shown in Figure 6. Only 8 sampling points of power requirement, which is composed of one point in current time and previous seven points, are necessary for the 3-order DWT. There is no need to know the whole working condition in advance, which is superior to Fourier transform. The DWT could also be used to process signals in unknown working condition.

3.3. Fuzzy Control. Fuzzy control strategy simulates human thinking based on fuzzy mathematics and fuzzy logic inference. Firstly the input variables are transformed into fuzzy ones, and then the rules preset in fuzzy controller are used for inference and decision, at last the reasoning results are defuzzified to control variables which are recognizable for real control system and intelligent control of the system will come true $[27,28]$.

In this part, the definition process of fuzzy controller $A$ is discussed in detail as follow. As the brake torque distribution strategy is not concerned in this paper, fuzzy controller B is not introduced.

As shown in Figure 7, A double-input and single-output fuzzy controller was designed $[29,30]$. The inputs of fuzzy controller are the engine load $f_{p}$ and the battery SOC $_{\text {bat }}$, and the output is power distribution coefficient $x_{\mathrm{fA}}$ :

$$
f_{p}=\frac{P_{\text {com_LF }}}{P_{\text {gen_max }}},
$$

where $P_{\text {gen_max }}$ is the maximum output power of the enginegenerator set.

The membership functions of the engine load $f_{p}$ and the battery SOC after fuzzification are shown in Figure 8, which are defined as follows:

$f_{p}:\{\mathrm{S}, \mathrm{M}, \mathrm{B}\}$, range $[0 \sim 1]$ that presents engine load varies from 0 to $P_{\text {gen_max }}$; 

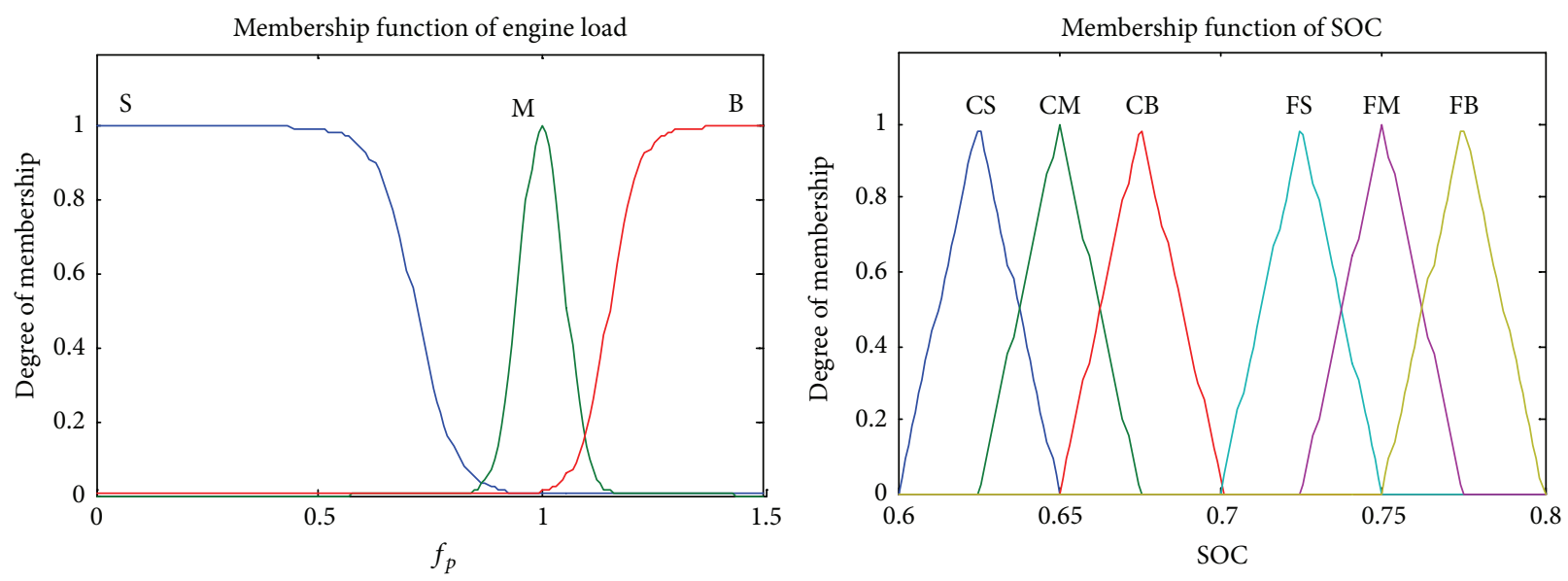

FIGURE 8: Membership function of fuzzy controller inputs.

TABLE 1: Membership function of $x_{\mathrm{fA}}$.

\begin{tabular}{lccccccc}
\hline$x_{\mathrm{fA}}$ & $\mathrm{VS}$ & $\mathrm{S}$ & $\mathrm{RS}$ & $\mathrm{M}$ & $\mathrm{RB}$ & $\mathrm{B}$ & $\mathrm{VB}$ \\
\hline Values & 0.8 & 0.85 & 0.9 & 0.95 & 1.05 & 1.1 & 1.2 \\
\hline
\end{tabular}

TABLE 2: Rules based on Mamdani fuzzy control algorithm.

\begin{tabular}{lcccccc}
\hline \multirow{2}{*}{$f_{p}$} & \multicolumn{5}{c}{ SOC } \\
& CS & CM & CB & FS & FM & FB \\
\hline S & VB & VB & B & RB & M & RS \\
M & VB & VB & B & M & RS & S \\
B & VB & B & RB & RS & S & VS \\
\hline
\end{tabular}

SOC: $\{\mathrm{CS}, \mathrm{CM}, \mathrm{CB}, \mathrm{FS}, \mathrm{FM}, \mathrm{FB}\}$, range $[0.6 \sim 0.8]$ that presents battery SOC varies from 0.6 to 0.8 .

The definition of distribution coefficient $x_{\mathrm{fA}}$ is shown in Table 1, and eighteen rules based on Mamdani fuzzy control algorithm were designed, as shown in Table 2 .

\section{Model of the Electric Drive System}

Simulation platform built in MATLAB/Simulink is shown in Figure 9. Models of Key components are built such as the engine-generator model, the battery model, the supercapacitor model, and the control strategy model.

4.1. Engine-Generator Model. The engine and generator are modeled as a whole according to rotation speed relationship between them. The generator is connected to DC bus through a three-phase bridge uncontrolled rectifier with filter capacitor $[31,32]$, and the equivalent circuit of PMSM (permanent magnet synchronous motor) with bridge rectifier is shown in Figure 10.
The internal resistance and torque losses of generator are neglected, and the voltage of DC bus and the electromagnetic torque are

$$
\begin{gathered}
U_{\mathrm{DC}}=K_{e} \omega_{g}-K_{x} \omega_{g} I_{\mathrm{DC}} \\
T_{e}=K_{e} I_{\mathrm{DC}}-K_{x} I_{\mathrm{DC}}^{2},
\end{gathered}
$$

where $K_{e} \omega_{g}$ is induced electromotive force, $K_{x} \omega_{g}$ is equivalent resistance, and $I_{\mathrm{DC}}$ is current of the DC bus.

The universal characteristics curve of a diesel engine is shown in Figure 11. There is not any mechanical joint between engine and sprocket, so the engine speed is not constrained by the travelling speed of the bulldozer any more. The engine could work on the best fuel consumption points which makes up the best fuel consumption curve, indicated by the dotted line in Figure $11[33,34]$. Based on the curve, the engine working point $\left(T_{\mathrm{eng}}^{*}, n_{e}^{*}\right)$ could be fixed after giving the target power requirement, and then the target voltage and current of the DC bus could be figured out according to formula (6).

In Figure 12, the target engine speed is regulated by the outer PI controller according to power errors between requirement and actual output; that is,

$$
\omega_{e}^{*}=\omega_{e_{-} \text {ref }}+\left(K_{p} \cdot e_{P}+K_{i} \cdot \int e_{P} d t\right),
$$

where $\omega_{e}^{*}$ is the target engine speed, $\omega_{e \text { _ref }}$ is the reference engine speed determined by the best fuel consumption curve, $e_{P}$ is the power error between requirement and real output, and $K_{p}$ and $K_{i}$ are parameters of the PI controller.

The output torque of the engine is controlled by inner PI loop to make sure of the engine working on the target speed. The input of the PI controller is error between target speed and real speed, and the output is target torque:

$$
T_{e}=\min \left\{\left(K_{p} \cdot e_{\omega}+K_{i} \cdot \int e_{\omega} d t\right), T_{e_{-} \max }\left(n_{e}\right)\right\},
$$

where $e_{\omega}$ is error between target speed and real speed, $K_{p}$ and $K_{i}$ are parameters of the PI controller, and $T_{e \_ \text {max }}\left(n_{e}\right)$ is the maximum torque of the engine at the current speed according to torque-speed curve. 
Energy distribution strategy of electric drive dozer

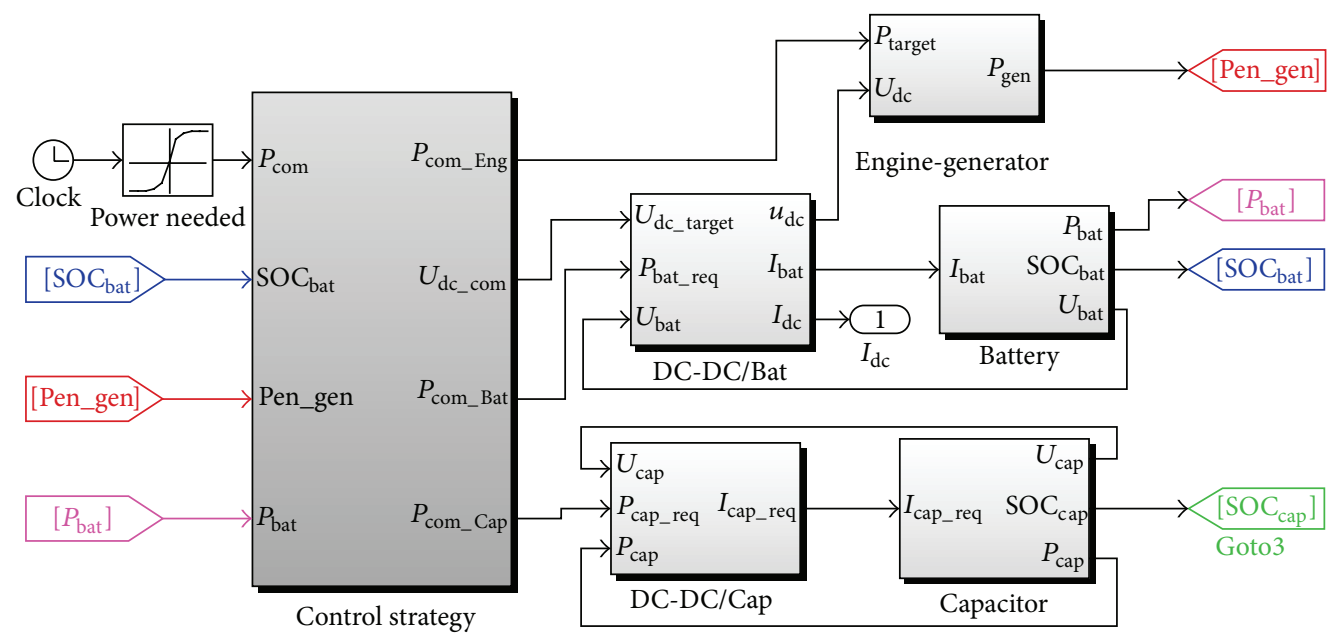

FIgURE 9: Simulation platform of the electric drive system.

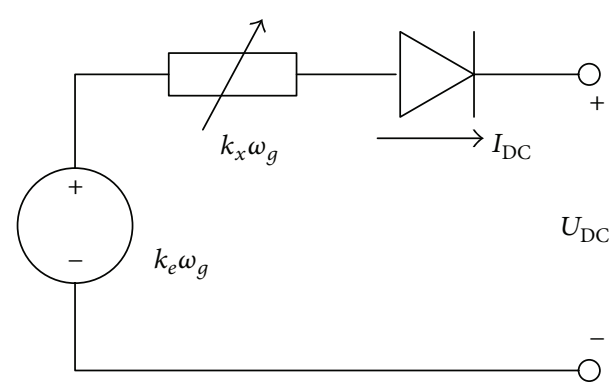

Figure 10: Equivalent circuit of engine-generator set.

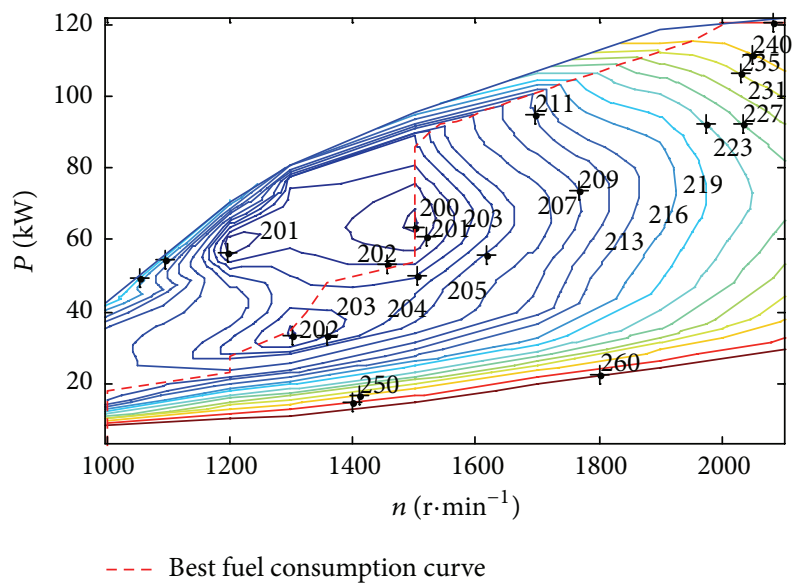

FIGURE 11: Universal characteristics curve of a diesel engine.

4.2. Battery Model. The equivalent resistance model is adopted, as shown in Figure 13 [35]. The terminal voltage of the battery is

$$
U_{\text {bat }}=V_{\text {bat }}-I_{\text {bat }} R_{s} \text {, }
$$

where $U_{\text {bat }}$ is the battery terminal voltage, $V_{\text {bat }}$ is the opencircuit voltage, $I_{\text {bat }}$ is the output current, and $R_{s}$ is the equivalent internal resistance.

The SOC of the battery pack is calculated by ampere-hour integration approach $[36,37]$ :

$$
\operatorname{SOC}(t)=\frac{Q_{0}-\int_{0}^{t} i(\tau) d \tau}{Q_{\max }},
$$

where SOC $(t)$ is battery's SOC, $Q_{0}$ is the initial capacity of the battery, $i(\tau)$ is battery's charge-discharge current, and $Q_{\max }$ is the maximum capacity of the battery.

4.3. Supercapacitor Model. The equivalent RC model is adopted which is shown in Figure 14 [38, 39].

The output current of supercapacitor is

$$
I_{\text {cap }}=I_{0}-\frac{1}{R_{P} C} \int I_{0} d t,
$$

where $C$ is the equivalent capacitance; $V_{\text {cap }}$ is the open-circuit voltage; $I_{0}$ is capacitor ideal output current; $I_{\text {cap }}$ is capacitor actual output current; $R_{s}$ is equivalent series resistance; and $R_{P}$ is equivalent parallel resistance.

The SOC of the supercapacitor is

$$
\mathrm{SOC}=\frac{V_{\text {cap }}-V_{\min }}{V_{\max }-V_{\min }},
$$

where $V_{\min }$ and $V_{\max }$ are the minimum and maximum opencircuit voltage of the capacitor, separately.

4.4. Control Strategy Model. The control strategy model is built in MATLAB/Simulink, based on multi-energy management strategy proposed in Section 3, which is shown in Figure 15. 


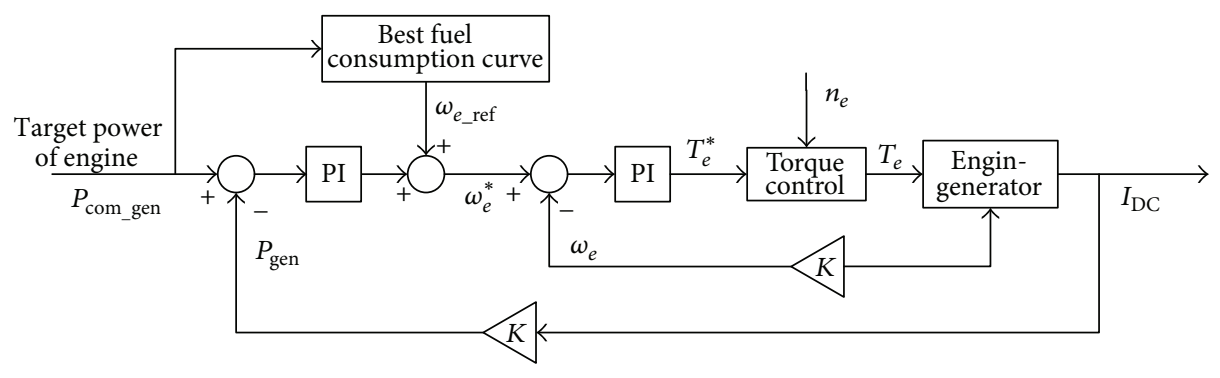

FIGURE 12: Engine-generator set control block diagram.

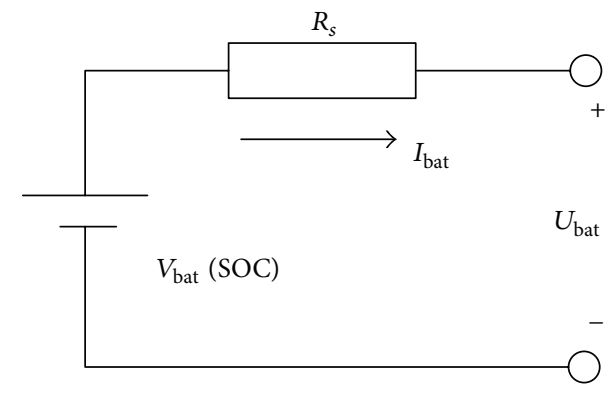

FIGURE 13: Equivalent circuit model of the battery pack.

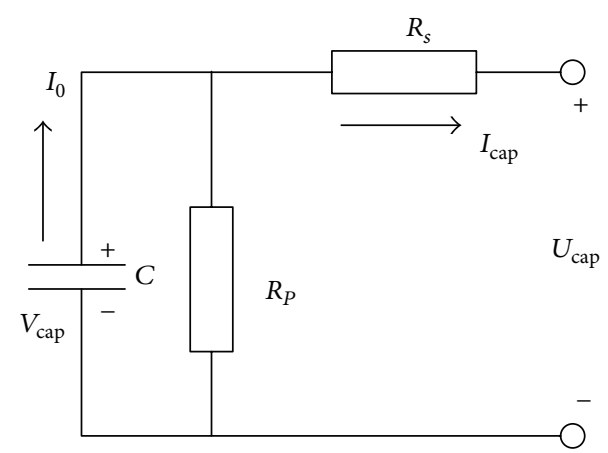

FIGURE 14: Equivalent RC model of supercapacitor.

\section{HILS Based on dSPACE}

5.1. Driver-Controller Based HILS Platform. The simulation platform of electric drive system of bulldozer is built based on dSPACE. The DS1005 PPC board is adopted and communication between controller and I/O interface is achieved by PHS (peripheral high-speed bus). The software environment is mainly made up of two parts: one is RTI used for code generation and downloading, and the other is testing software. Models built in MATLAB/Simulink are transformed into $\mathrm{C}$ codes which are sent to dSPACE by RTI. The testing software includes ControlDesk, Auto experiment and parameter adjustment software-MLIB/MTRACE, and real-time animation software-RealMotion [40].

The structure of driver-controller based HILS platform is shown in Figure 16. The driver's operating signal is transmitted to general controller after A/D conversion, and the controller sends power distribution orders according to driver's input and bulldozer's state to power sources through CAN bus. Hardware of HILS platform is shown in Figure 17.

5.2. Result Analysis. The power distribution result of the front power chain is shown in Figure 18. The engine-generator set serves as the main power source and most of power requirement is expected to be provided by it. Except the period between $10 \mathrm{~s}$ to $15 \mathrm{~s}$, as the shoveling resistance is too heavy and the power requirement exceeds the maximum output of the engine-generator, the rest of power requirement is designed to be provided by the battery. Output of the supercapacitor changes much more quickly than that of the battery in order to follow target power requirement.

The input and output of the fuzzy controller are shown in Figure 19. When the battery SOC is higher than 0.7, the distribution coefficient is small and the battery pack will discharge; in contrast, when the battery SOC is lower than 0.7 , the distribution coefficient is large and the battery pack will charge. So the fuzzy control rules make the SOC vary from 0.6 to 0.8 and basically stabilize around 0.7 .

The target and actual power output of the enginegenerator set are shown in Figure 20. It is observed that the actual output basically follows the target power output except some error when target output changes suddenly, and the error is mainly caused by the switching time when engine changes its working state.

The working points of the engine are mostly on the best fuel consumption curve which makes engine efficient, as shown in Figure 21. Parts of engine working points are far away from the best fuel consumption curve, especially in the low-speed area. Because in low-speed area, target output power changes will lead to huge changes of target speed according to the best fuel consumption curve, which makes engine switch working point too often. The responding speed of engine is slow, so it could not work on the best fuel consumption point when changing working state.

As shown in Figure 22, the battery SOC changes little and is basically controlled around 0.7 in order to obtain high charge/discharge efficiency. On the contrary, the supercapacitor SOC varies in a large scale from 0.45 to 0.75 .

The charge/discharge voltage and current of the battery and the capacitor are shown in Figures 23 and 24, respectively. In Figure 23(a), the terminal voltage of the battery changes little from $143 \mathrm{~V}$ to $150 \mathrm{~V}$, because the battery SOC stabilizes around 0.7 so that the open-circuit voltage of the battery 

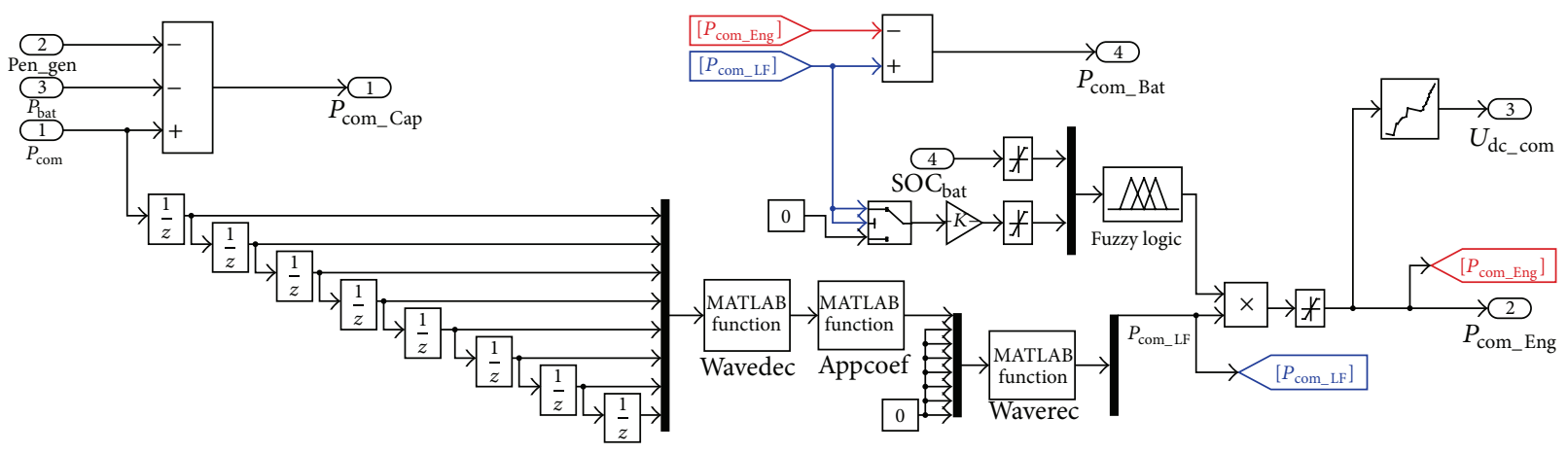

FIGURE 15: Control strategy model based on MATLAB/Simulink.
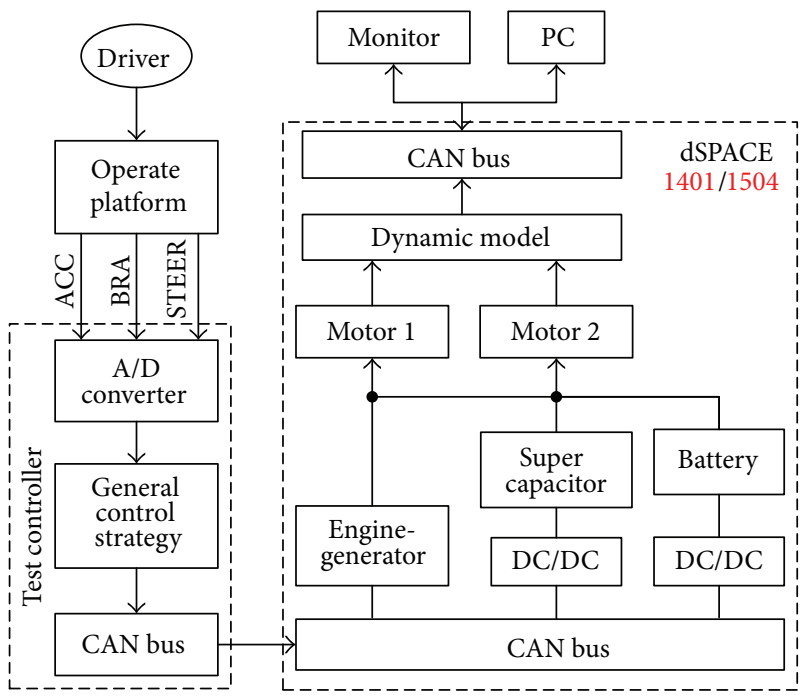

FIGURE 16: Structure of driver-controller based HILS.

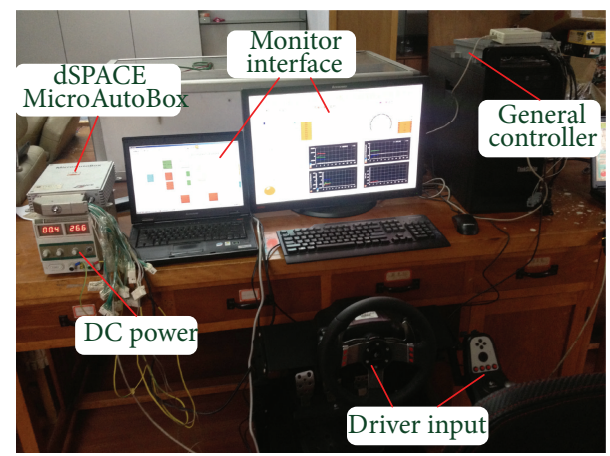

FIGURE 17: Hardware of HILS platform.

changes little. On the other hand, as the capacitor SOC changes in a large scale, the terminal voltage of the capacitor changes greatly from $90 \mathrm{~V}$ to $110 \mathrm{~V}$. In Figure 24, the battery current changes from $-60 \mathrm{~A}$ to $250 \mathrm{~A}$, and the capacitor current changes with high frequency from $-200 \mathrm{~A}$ to $400 \mathrm{~A}$.
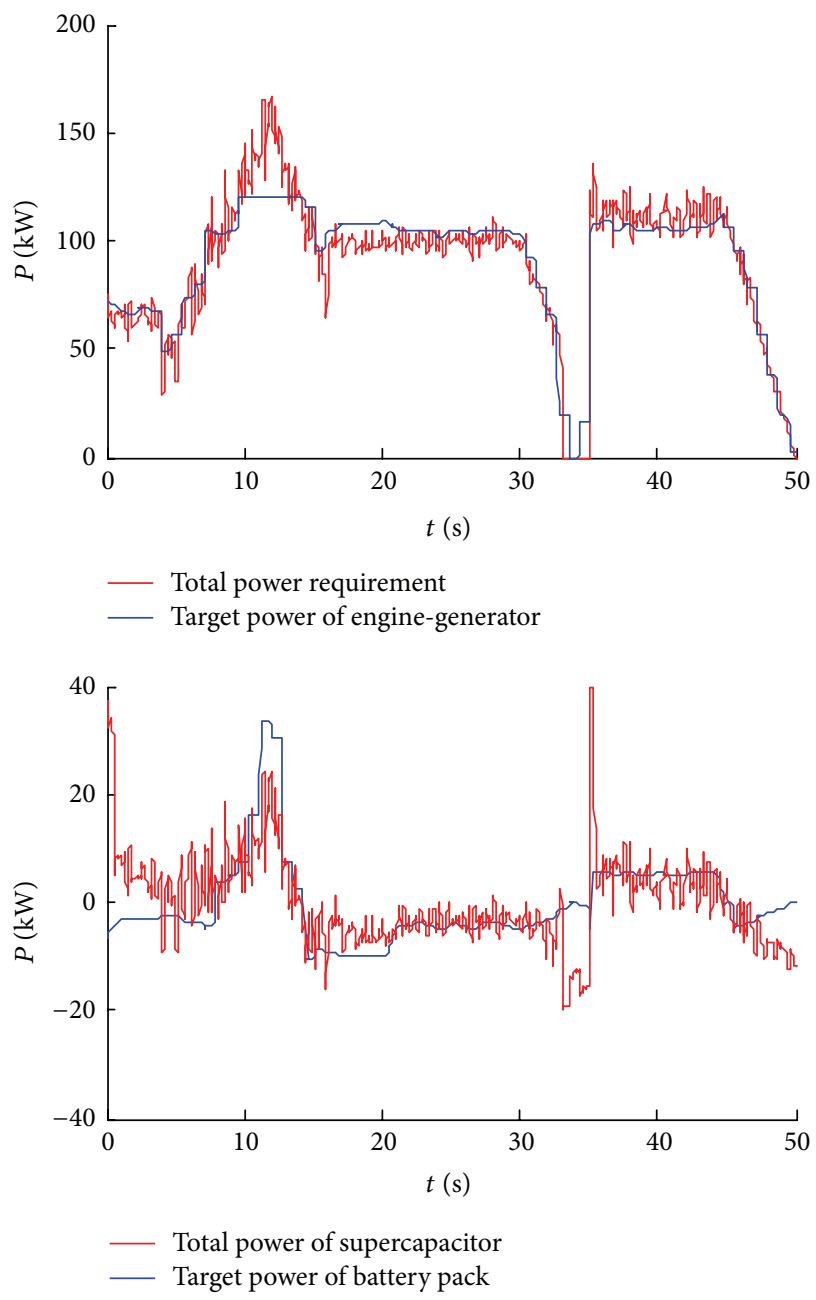

Figure 18: Power distribution result of front power chain.

\section{Conclusions}

The multi-energy management strategy of the electric drive system of the tracked bulldozer is taken as the research subject in the thesis. Firstly, based on power requirement of typical working condition of a tracked bulldozer, the power distribution strategy for three energy sources in the front 

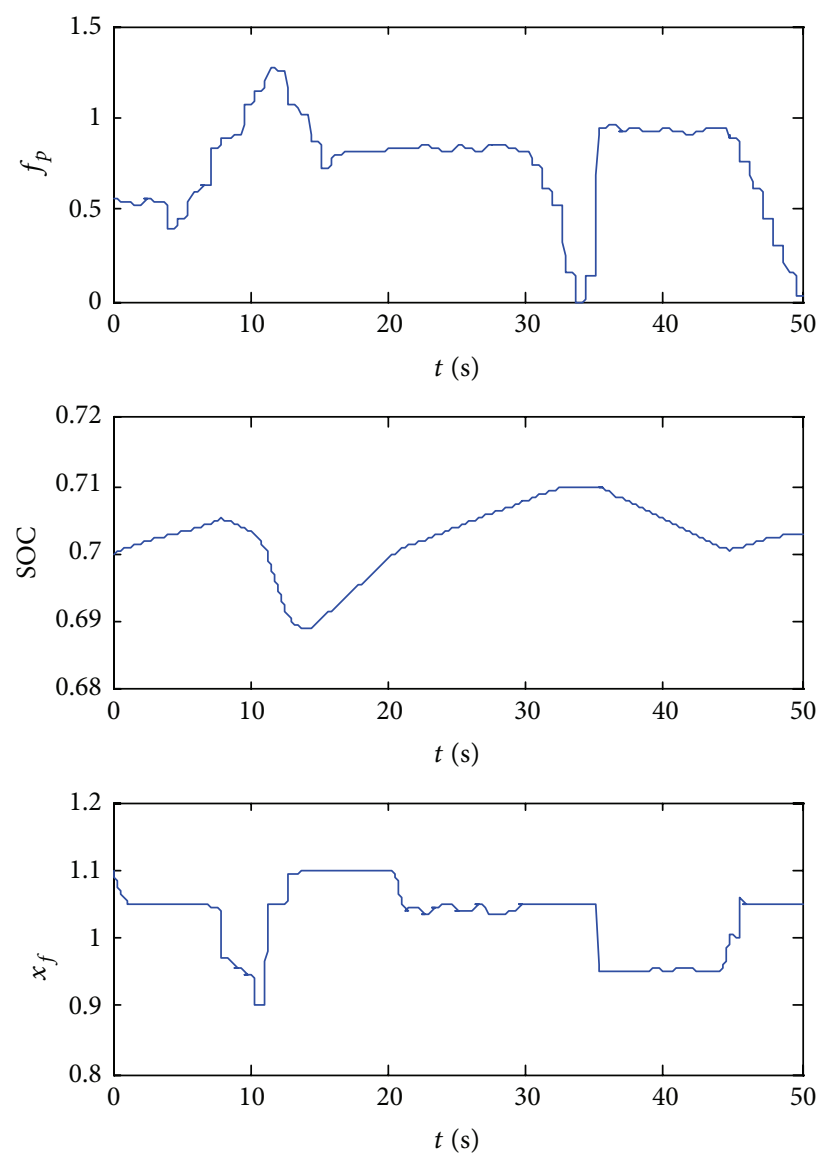

FIGURE 19: Input and output curves of fuzzy controller.

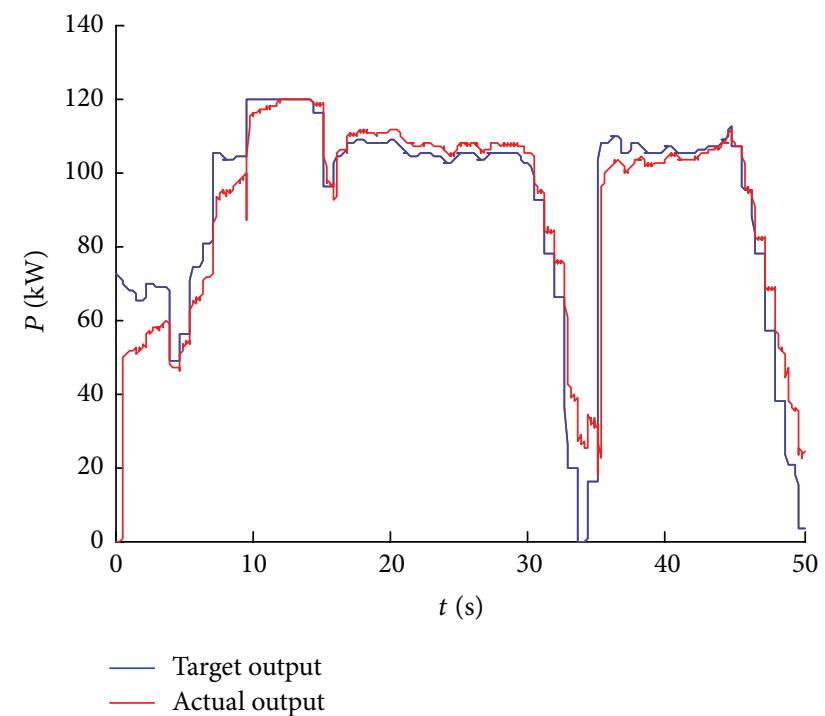

Figure 20: Power following character of engine.

power chain was proposed by using wavelet theory and fuzzy control theory. Secondly, the electric drive system simulation platform was built in MATLAB/Simulink. At last, a drivercontroller based HILS (hardware-in-the-loop simulation)

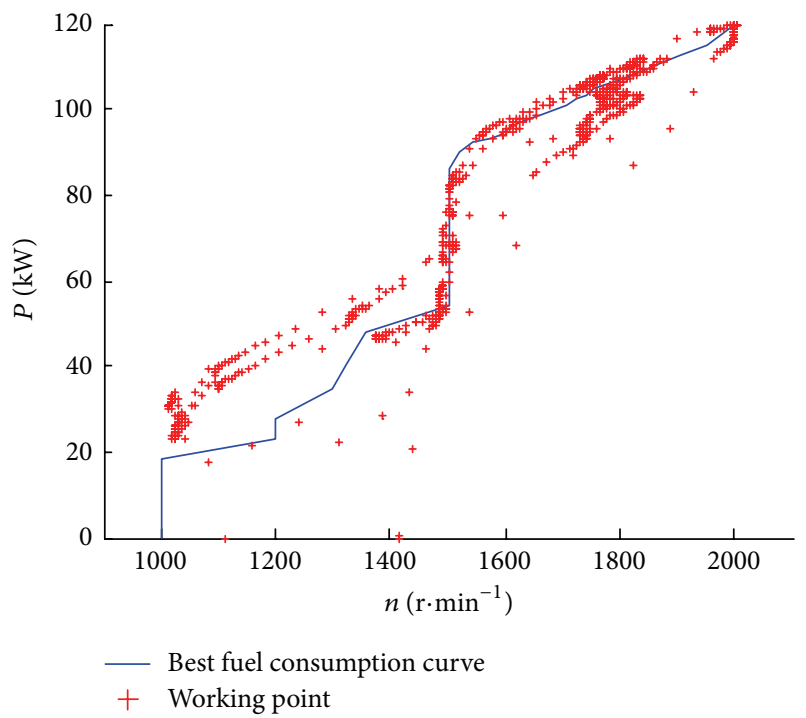

FIGURE 21: Actual working point of engine.

platform was built and the multi-energy management strategy was verified. The HILS result indicates the following.

(1) Front power chain's power output responds quickly enough to the back power chain's requirement. 


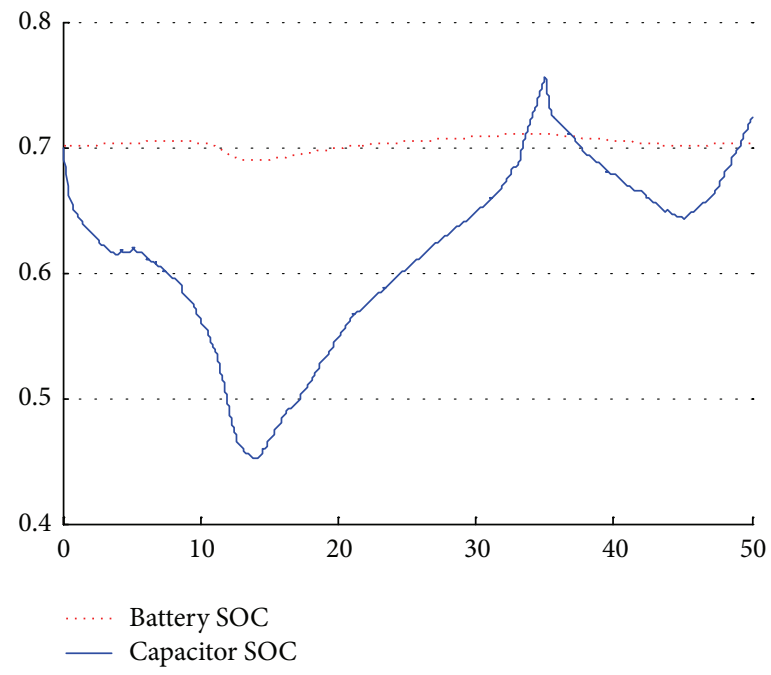

FIGURE 22: SOC changes of battery and supercapacitor.

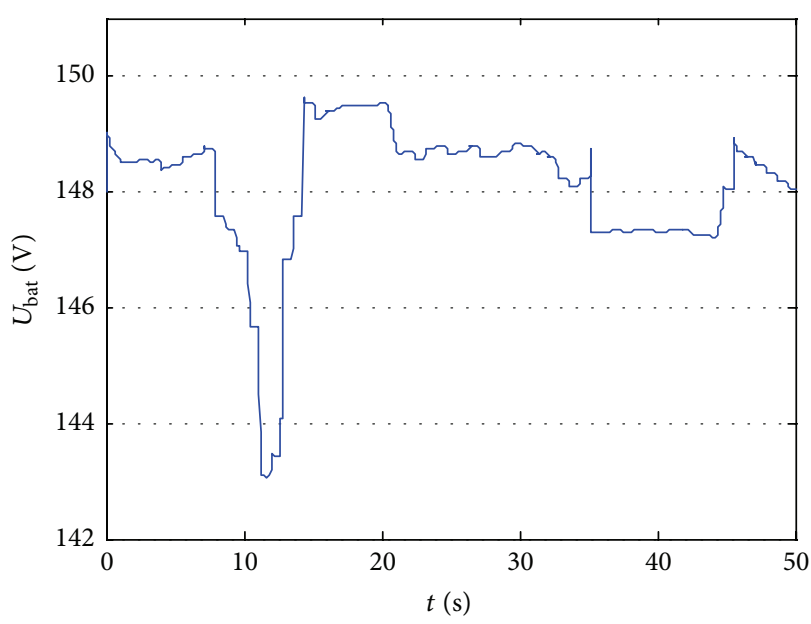

(a)

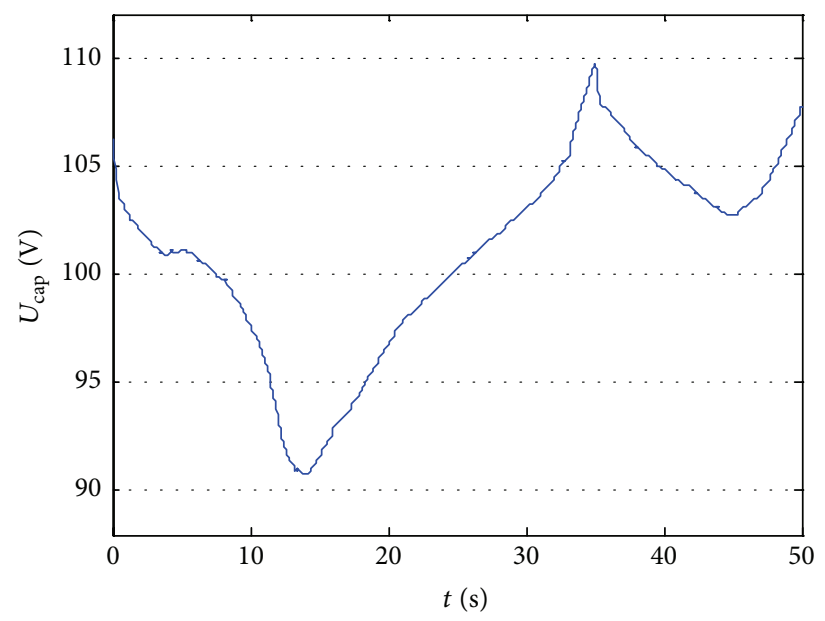

(b)

FIGURE 23: Charge/discharge voltage of energy storage element.

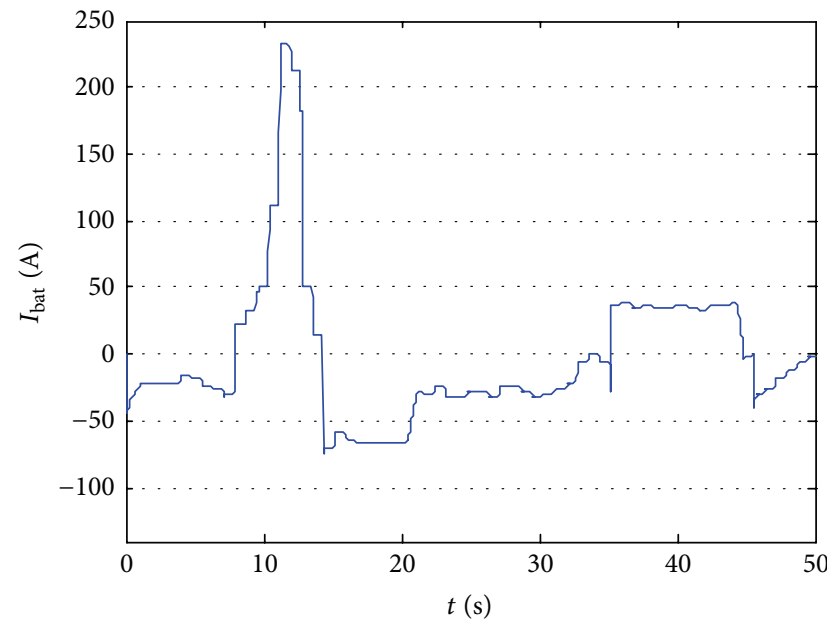

(a)

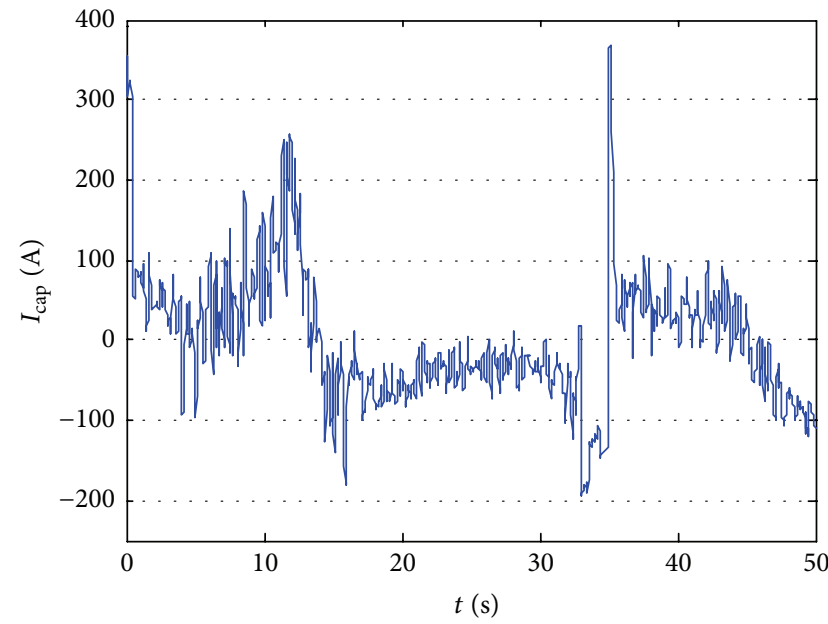

(b)

FIgURE 24: Charge/discharge current of energy storage element. 
(2) The engine-generator set works near the best fuel consumption curve which makes it more efficient.

(3) The battery pack's charge-discharge frequency and current are low and the SOC stabilizes around 0.7, which are conductive to improve battery's working life.

(4) The supercapacitor responds to instantaneous power requirement quickly and its SOC varies from 0.45 to 0.75 .

Above all, on the basis of meeting the power demand, the multi-energy management strategy makes distribution among three power sources generally considering fuel economy, response character, and working life of power source, which can be used in real-time control of the electric drive bulldozer.

\section{Conflict of Interests}

The authors declare that there is no conflict of interests regarding the publication of this paper.

\section{References}

[1] M. Wachtmeister, "Overview and analysis of environmental and climate policies in China's automotive sector," The Journal of Environment \& Development, vol. 22, no. 3, pp. 284-312, 2013.

[2] P. Zhang, F. W. Yan, and C. Q. Du, "A comprehensive analysis of energy management strategies for hybrid electric vehicles based on bibliometrics," Renewable and Sustainable Energy Reviews, vol. 48, pp. 88-104, 2015.

[3] H. Banvait, S. Anwar, and Y. Chen, "A rule-based energy management strategy for Plugin Hybrid Electric Vehicle (PHEV)," in Proceedings of the American Control Conference (ACC '09), pp. 3938-3943, St. Louis, Mo, USA, June 2009.

[4] C. F. Pan, L. Chen, L. Chen, H. Jiang, Z. Li, and S. Wang, "Research on motor rotational speed measurement in regenerative braking system of electric vehicle," Mechanical Systems and Signal Processing, vol. 66-67, pp. 829-839, 2016.

[5] N. J. Schouten, M. A. Salman, and N. A. Kheir, "Energy management strategies for parallel hybrid vehicles using fuzzy logic," Control Engineering Practice, vol. 11, no. 2, pp. 171-177, 2003.

[6] B. Baumann, G. Rizzoni, and G. Washington, Intelligent Control of the Ohio State University Hybrid-Electric Vehicle, Elsevier Science Publisher B.V., Amsterdam, The Netherlands, 1998.

[7] H.-D. Lee and S.-K. Sul, "Fuzzy-logic-based torque control strategy for parallel-type hybrid electric vehicle," IEEE Transactions on Industrial Electronics, vol. 45, no. 4, pp. 625-632, 1998.

[8] S. G. Li, S. M. Sharkh, F. C. Walsh, and C. N. Zhang, "Energy and battery management of a plug-in series hybrid electric vehicle using fuzzy logic," IEEE Transactions on Vehicular Technology, vol. 60, no. 8, pp. 3571-3585, 2011.

[9] W. W. Xiong, Y. Zhang, and C. L. Yin, "Optimal energy management for a series-parallel hybrid electric bus," Energy Conversion and Management, vol. 50, no. 7, pp. 1730-1738, 2009.

[10] A. Poursamad and M. Montazeri, "Design of genetic-fuzzy control strategy for parallel hybrid electric vehicles," Control Engineering Practice, vol. 16, no. 7, pp. 861-873, 2008.
[11] J. Wu, C.-H. Zhang, and N.-X. Cui, "Fuzzy energy management strategy for a hybrid electric vehicle based on driving cycle recognition," International Journal of Automotive Technology, vol. 13, no. 7, pp. 1159-1167, 2012.

[12] M. Derakhshan and K. H. Shirazi, "Optimized fuzzy controller for a power-torque distribution in a hybrid vehicle with a parallel configuration," Proceedings of the Institution of Mechanical Engineers Part D: Journal of Automobile Engineering, vol. 228, no. 14, pp. 1654-1674, 2014.

[13] M. Mohebbi, M. Charkhgard, and M. Farrokhi, "Optimal neuro-fuzzy control of parallel hybrid electric vehicles," in Proceedings of the IEEE Vehicle Power and Propulsion Conference (VPPC '05), pp. 252-256, IEEE, September 2005.

[14] Z. Chen, M. A. Masrur, and Y. L. Murphey, "Intelligent vehicle power management using machine learning and fuzzy logic," in Proceedings of the IEEE International Conference on Fuzzy Systems (FUZZ '08), pp. 2351-2358, Hong Kong, June 2008.

[15] R. Langari and J.-S. Won, "Intelligent energy management agent for a parallel hybrid vehicle-part I: system architecture and design of the driving situation identification process," IEEE Transactions on Vehicular Technology, vol. 54, no. 3, pp. 925934, 2005.

[16] J.-S. Won and R. Langari, "Intelligent energy management agent for a parallel hybrid vehicle-part II: torque distribution, charge sustenance strategies, and performance results," IEEE Transactions on Vehicular Technology, vol. 54, no. 3, pp. 935-953, 2005.

[17] M. W. T. Koot, "A dynamic programming approach for power management in wireless video sensor networks," IEEE Transactions on Vehicular Technology, vol. 58, pp. 843-854, 2006.

[18] J. Liu and H. Peng, "Modeling and control of a power-split hybrid vehicle," IEEE Transactions on Control Systems Technology, vol. 16, no. 6, pp. 1242-1251, 2008.

[19] J. Wu, C.-H. Zhang, and N.-X. Cui, "Real-time energy management of parallel hybrid electric vehicle based on BP neural network," Electric Machines and Control, vol. 12, no. 5, pp. 610$614,2008$.

[20] K. Zhao and Y. Luo, "Real-time optimization supervisory control of HEV powertrain," in Proceedings of the International Conference on Transportation Engineering (ICTE '07), pp. 2852 2857, July 2007.

[21] J. Z. Hao, Normal Use and Maintenance of Bulldozer, China Machine Press, Beijing, China, 2010.

[22] A. Jossen, "Fundamentals of battery dynamics," Journal of Power Sources, vol. 154, no. 2, pp. 530-538, 2006.

[23] R. M. Strzelecki and G. Benysek, Energy Storage Systems, Springer, London, UK, 2008.

[24] R. L. Spyker and R. M. Nelms, "Analysis of double-layer capacitors supplying constant power loads," IEEE Transactions on Aerospace and Electronic Systems, vol. 36, no. 4, pp. 1439$1443,2000$.

[25] B. J. Falkowski, "Forward and inverse transformations between haar wavelet and arithmetic functions," Electronics Letters, vol. 34, no. 11, pp. 1084-1085, 1998.

[26] X. Wang, "Moving window-based double haar wavelet transform for image processing," IEEE Transactions on Image Processing, vol. 15, no. 9, pp. 2771-2779, 2006.

[27] Y. Gao and M. Ehsani, "A mild hybrid vehicle drive train with a floating stator motor-configuration, control strategy, design and simulation verification," in Proceedings of the Future Car Congress, Arlington, Va, USA, June 2002. 
[28] F. R. Salmasi, "Control strategies for hybrid electric vehicles: evolution, classification, comparison, and future trends," IEEE Transactions on Vehicular Technology, vol. 56, no. 5, pp. 23932404, 2007.

[29] E. H. Mamdani and S. Assilian, "An experiment in linguistic synthesis with a fuzzy logic controller," International Journal of Man-Machine Studies, vol. 7, no. 1, pp. 1-13, 1975.

[30] S. N. Sivanandam, S. Sumathi, and S. N. Deepa, Introduction to Fuzzy Logic Using MATLAB, Springer, Berlin, Germany, 2007.

[31] A. Sciarretta and L. Guzzella, "Control of hybrid electric vehicles," IEEE Control Systems Magazine, vol. 27, no. 2, pp. 6070, 2007.

[32] J. M. Liu, Modeling, Configuration and Control Optimization of Power-Split Hybrid Vehicles, University of Michigan, Detroit, Mich, USA, 2007.

[33] C.-C. Lin, H. Peng, J. W. Grizzle, and J.-M. Kang, "Power management strategy for a parallel hybrid electric truck," IEEE Transactions on Control Systems Technology, vol. 11, no. 6, pp. 839-849, 2003.

[34] N. Jalil, N. A. Kheir, and M. Salman, "A rule-based energy management strategy for a series hybrid vehicle," in Proceedings of the American Control Conference, vol. 1, pp. 689-693, IEEE, Albuquerque, NM, USA, June 1997.

[35] H. He, R. Xiong, H. Guo, and S. Li, "Comparison study on the battery models used for the energy management of batteries in electric vehicles," Energy Conversion and Management, vol. 64, pp. 113-121, 2012.

[36] W. Waag, C. Fleischer, and D. U. Sauer, "On-line estimation of lithium-ion battery impedance parameters using a novel variedparameters approach," Journal of Power Sources, vol. 237, pp. 260-269, 2013.

[37] W. Waag, C. Fleischer, and D. U. Sauer, "Adaptive on-line prediction of the available power of lithium-ion batteries," Journal of Power Sources, vol. 242, pp. 548-559, 2013.

[38] E. Faggioli, P. Rena, V. Danel, X. Andrieu, R. Mallant, and H. Kahlen, "Supercapacitors for the energy management of electric vehicles," Journal of Power Sources, vol. 84, no. 2, pp. 261-269, 1999.

[39] D. Rotenberg, A. Vahidi, and I. Kolmanovsky, "Ultracapacitor assisted powertrains: modeling, control sizing, and the impact on fuel economy," in Proceedings of the American Control Conference, pp. 981-987, Seattle, Wash, USA, September 2008.

[40] D. Zhu, "Reliability-aware dynamic energy management in dependable embedded real-time systems," in Proceedings of the 12th IEEE Real-Time and Embedded Technology and Applications Symposium (RTAS '06), pp. 397-407, IEEE, April 2006. 


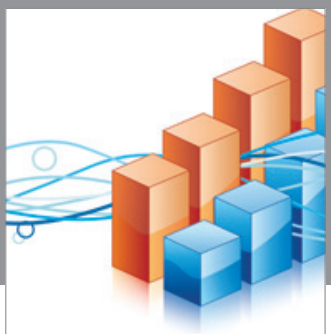

Advances in

Operations Research

vatem alat4

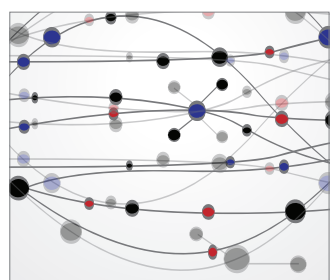

\section{The Scientific} World Journal
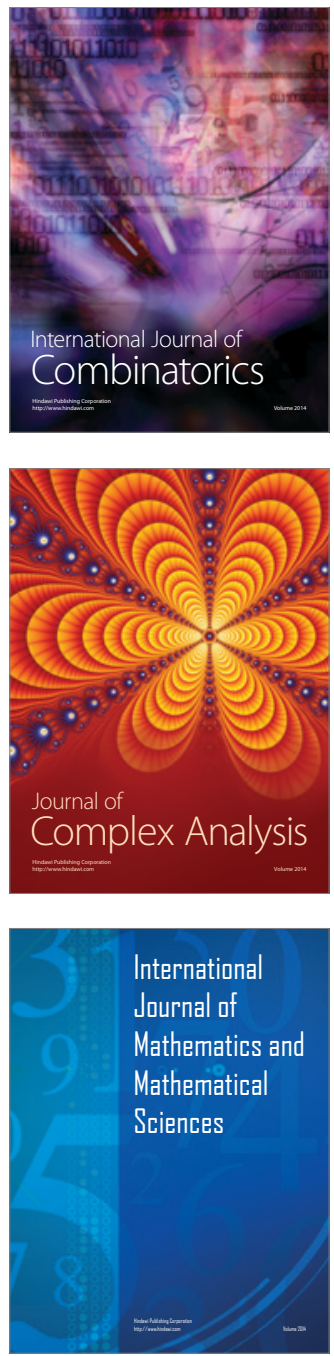
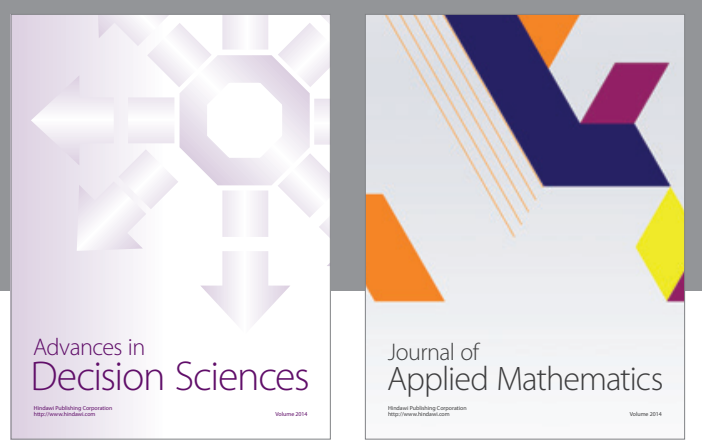

Algebra

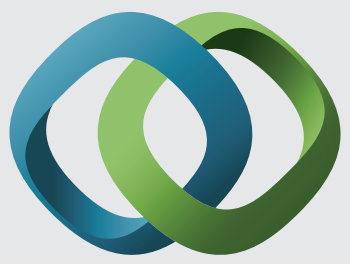

\section{Hindawi}

Submit your manuscripts at

http://www.hindawi.com
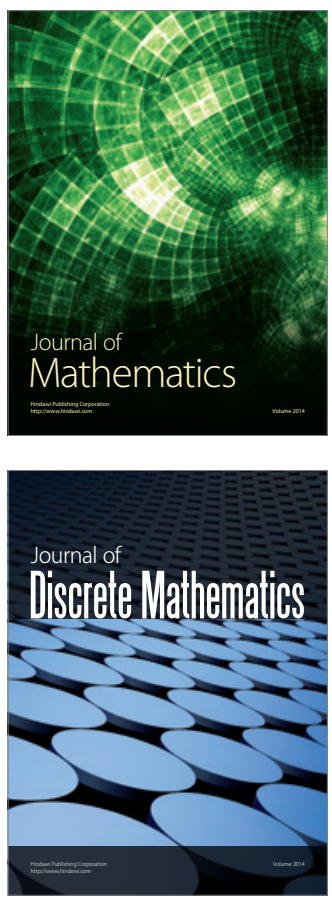

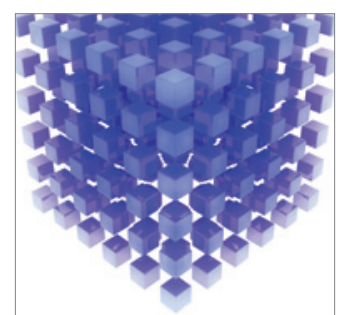

Mathematical Problems in Engineering
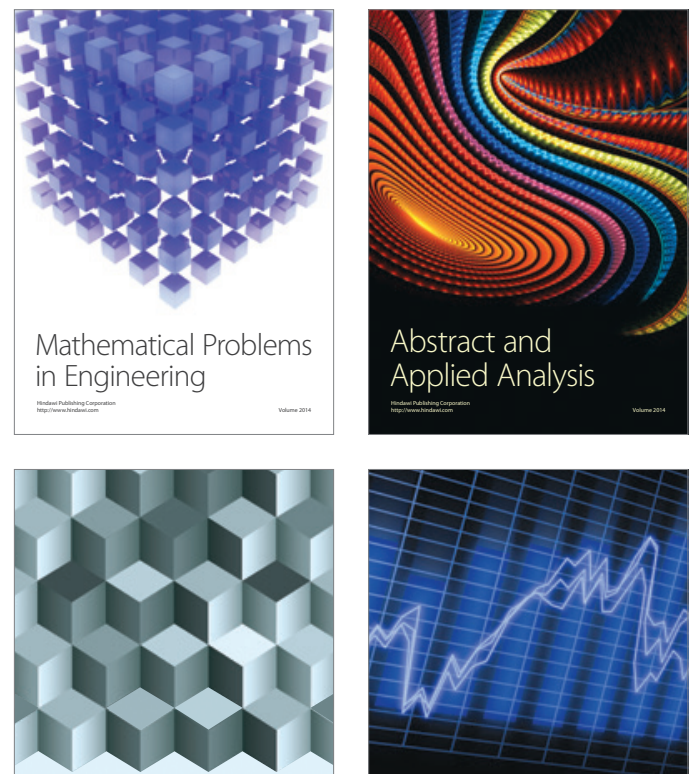

Journal of

Function Spaces

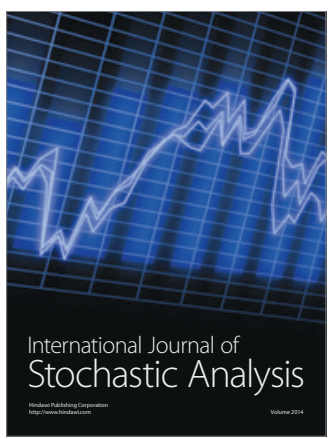

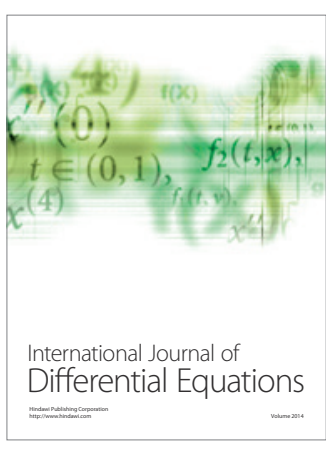
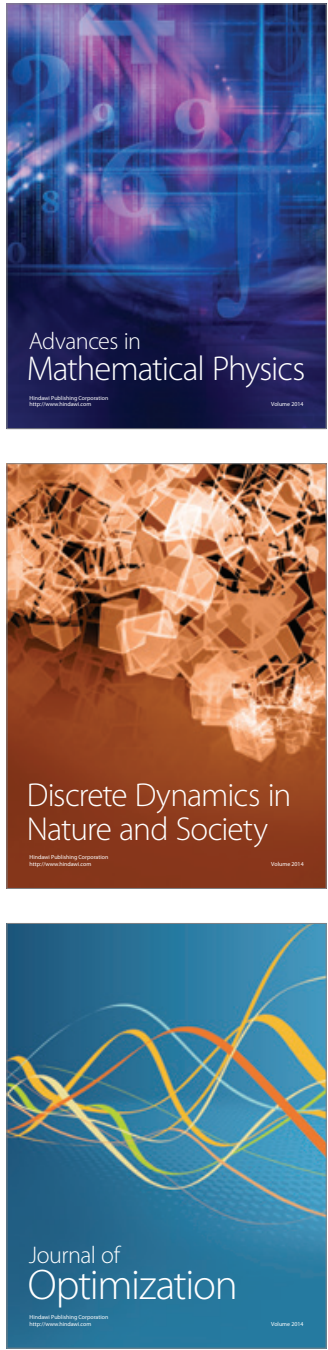